\title{
6 Carbon from waste source for Li-ion battery
}

\subsection{Introduction}

Energy generation and use depends heavily on fossil fuels, and it severely impacts the global economics and living sustainability [1]. Completely shifting to clean energy production and consumption is vital for the present and future generations. Electrochemical energy storage and conversion can be implemented by various devices such as (rechargeable) batteries, fuel cells and electrochemical capacitors (ECs). They are considered fundamental elements for developing a sustainable energy society. In particular, a battery [2] is an electrochemical power source comprising several cells, which are connected in series or parallel or in combination in order to deliver the required output voltage and energy.

In ancient Greece, Thales observed that rubbing amber could generate an electric charge [3]. In between $250 \mathrm{BC}$ and $\mathrm{AD}$ 640, there are evidences for the use of a storage system known as the "Baghdad batteries" [4]. In 1748, Benjamin Franklin first coined the term "battery" to describe an array of charged glass plates. In the 1780s, Luigi Galvani demonstrated the electrical basis of nerve impulses, which is widely called as the frog leg experiment. The Italian physicist Alessandro Volta in 1800 invented the chemical battery, Voltaic pile. Volta discovered that an electrical current is generated when metals come in contact with chemicals. John Frederic Daniell in 1820 improved the voltaic cell using copper $(\mathrm{Cu})$ and zinc $(\mathrm{Zn})$ plates as electrodes and sulfates of respective metals as electrolytes, and termed as the Daniell cell, which was later used for operating telegraphs and doorbells. In the 1830s, Michael Faraday conducted experiments with a ferrite ring and device called a battery. Carbon-zinc battery was developed by Georges Leclanché in the 1860s. The wet cell consisted of electrodes that were plunged into a body of electrolyte fluid, which was manufactured easily and exhibited acceptable shelf life [5]. An improved version known as a dry cell was later developed by sealing the cell and changing the fluid electrolyte to a wet paste. Raymond Gaston Planté in the 1860s invented the first practical storage lead acid battery. He immersed two thin solid lead plates separated by rubber sheets in a dilute sulfuric acid solution to make a

Pravin Jagdale, Krishna Rajan, Jijeesh Ravi Nair, Massimo Rovere, Alberto Tagliaferro, Claudio Gerbaldi, Department of Applied Science and technology (DISAT), Politecnico di Torino, Torino, Italy

Pravin Jagdale, Italian Institute of technology (IIT), Torino, Italy

Gemma Rius, Institute of Microelectronics of Barcelona, Bellaterra, Spain

Ә Open Access. (C) 2020 Pravin Jagdale et al., published by De Gruyter. (c) BY-NC-ND This work is licensed under a Creative Commons Attribution-NonCommercial-NoDerivatives 4.0 International License.

https://doi.org/10.1515/9783110479133-006 
secondary battery. Later in 1900, Thomas Edison developed the nickel (Ni) storage battery and later in 1905 he developed the Ni-iron (Fe) battery [6].

A cell is made of three major components: a positive electrode (cathode), a negative electrode (anode) and a separator. A separator is soaked in organic carbonatebased liquid electrolyte. The electrolyte contains dissociated salts, which facilitate ion transfer between the two electrodes. Once these electrodes are externally connected to a device, the chemical reactions occur at the electrodes. The process generates electrons and enables the current to flow. The terms anode and cathode are applicable generally for primary batteries, but are not suitable for secondary (rechargeable) batteries. During charging and discharging the direction of electron flow changes, however, the electrodes retain their polarity. Thus, the terms negative and positive electrodes are most suited to describe the terminals of a rechargeable battery system.

The energy storage system can be primary or secondary. Primary cells are designed to discharge once and can be discarded after use. If one attempts to recharge a primary cell, then it can present serious safety hazards. The examples of primary cells include carbon-zinc and alkaline cells. Primary cells having lithium (Li) as an anode are called Li cells irrespective of the nature of the cathode. Such cells are separated into two types: cells with solid cathodes (e.g., $\mathrm{Li}-\mathrm{MnO}_{2}$ ) and cells with liquid cathodes (e.g., Li-SO $\mathrm{S}_{2}$ [7]. Reserve batteries are a special-purpose primary cell, which are used for applications that require a long inactive shelf period followed by intense discharge and unusual operational conditions. The oldest form of a rechargeable battery system in use is the wet cell lead acid battery. It represents one of the worst energy-to-weight ratios. However, it delivers good power-to-weight ratio along with good energy-to-volume ratio compared to other type of batteries. It is cheap and can supply high surge currents needed in starter motors along with low manufacturing cost.

Li metal [8] has been selected as a good choice due to its low mass density, smaller size compared to other known battery materials as charge carrier, and a high mobility and fast transport speed. These features give Li-based secondary batteries a distinct advantage over other battery systems such as Ni-cadmium (Cd) and lead acid batteries. $\mathrm{Cd}$ is highly toxic and heavier, and the same problems are applied to lead as well. The discovery (1970s) of several intercalating inorganic compounds was monumental in the development and widespread use of high-energy rechargeable Li-based batteries. Whittingham et al. introduced the concept of electrochemical intercalation and its potential use [9]. The discovery and the understanding of the intercalating compounds led to the development of rechargeable $\mathrm{Li}$ batteries using Li insertion compounds as positive electrodes and Li metal as the negative electrode ( $\mathrm{Li}$ metal battery). The first Li metal battery cell was introduced by Exxon et al. [10] in which they used titanium disulfide $\left(\mathrm{TiS}_{2}\right)$ as positive electrode, Li metal as negative electrode and $\mathrm{Li}$ perchlorate in dioxolane as the electrolyte. The safety concerns related to the use of Li metal as anode was addressed via 
alternative approaches. It led to the modification of either the electrode or the electrolyte. Murphy et al. [11] and Scrosati et al. [12] demonstrated that Li metal can be replaced by an insertion host having low standard reduction potential. In the early 1990s, the concept of using electrodes having $\mathrm{Li}^{+}$-ion insertion capabilities led to the development of today's $\mathrm{Li}^{+}$-ion batteries. The presence of $\mathrm{Li}$ in the anode in ionic form rather than in metallic form of $\mathrm{a} \mathrm{Li}^{+}$-ion cell resolved the dendrite problem, which was inherited by Li metal cells.

In the 1980s, Goodenough et al. [13, 14] proposed the high-voltage metal oxides $\left(\mathrm{Li}_{x} \mathrm{MO}_{2}\right.$, where $\mathrm{M}=\mathrm{Ni}$, cobalt (Co) or manganese (Mn)) as cathodes for $\mathrm{Li}^{+}$-ion cells. The discovery of highly reversible, low-voltage $\mathrm{Li}^{+}$-ion intercalation/deintercalation process in graphite led to the creation of the first $\mathrm{Li}^{+}$-ion cell based on $\mathrm{C} / \mathrm{LiCoO}_{2}$, which was commercialized by Sony Corporation. Such cells exhibited an operational voltage of $3.6 \mathrm{~V}$ (3 times vs. alkaline systems), gravimetric energy densities of $150 \mathrm{Wh} / \mathrm{kg}$ (2-3 times vs. Ni-Cd (cadmium) batteries) and a cycle life of at least 500 discharges.

Presently, $\mathrm{Li}^{+}$-ion batteries are the fastest growing storage devices. The salient features of today's commercial $\mathrm{Li}^{+}$-ion batteries are

- high operating voltage between 3.6 and $4.2 \mathrm{~V}$,

- compact,

- lightweight,

- high energy density,

- fast charging,

- low self-discharge,

- not suffer from memory effect,

- use between -20 and $+60^{\circ} \mathrm{C}$ and

- recharge for more than 1,000 cycles.

The $\mathrm{Li}^{+}$-ion rechargeable cell working mechanism depends on an "intercalation/deintercalation" process [15]. The storage processes, which do not involve intercalation are called "insertion/de-insertion" process. Indeed, the term "intercalation" is used for layered-type host substances (e.g., graphite, $\mathrm{TiS}_{2}$, molybdenum disulfide $\left(\mathrm{MoS}_{2}\right)$ or lithium cobalt oxide $\left.\left(\mathrm{LiCoO}_{2}\right)\right)$, while "insertion" is used for 3-D materials that have narrow channel cavities. The charge/discharge process is reversible where the $\mathrm{Li}^{+}$ions move back and forth between the anode and cathode. The process presented the $\mathrm{Li}^{+}$-ion battery names such as rocking chair $[16]$, swing $[17,18]$ or shuttlecock [19].

In general, for a $\mathrm{Li}^{+}$-ion cell:

- The electrode materials must possess high specific capacity and durability.

- The electrolyte must exhibit high ionic conductivity at ambient and subambient temperatures.

- The electrolyte must have good interfacial properties.

- The materials should be economical, eco-friendly, easily available and safe. 
Thus, the selection of right materials is important to produce a sustainable and an efficient battery pack.

A successful electrode should meet a number of criteria:

- The intercalation/insertion compound should have large number of available Li sites.

- $\mathrm{The}^{+} \mathrm{Li}^{+}$ions insertion/de-insertion process should be reversible.

- The host material should not undergo structural changes.

- The host material should be accessing the multiple oxidation states of the transition metals.

- The compounds should possess good electronic and ionic conduction.

- The electrodes must be stable over the working voltage range.

- The electrodes should not undergo dissolution into the electrolyte.

- It should be environmentally friendly and easy to produce.

Li metal is an ideal anode for rechargeable batteries due to its high potential and specific capacity. It is widely used as an anode in primary Li cells. However, dendritic growth, cost, safety hazards and poor recharge ability prevents its practical use in secondary batteries. The issues are addressed by the use of Li alloys (with $\mathrm{Al}$ or $\mathrm{Si}$ ). Unfortunately, the alloy anodes undergo severe volume changes during the cycling process. Nevertheless, the urge for the development of solid-state (ceramic/polymer) electrolytes are a promising approach to realize the use of safe $\mathrm{Li}$ metal rechargeable batteries. The standard and commercialized anode for $\mathrm{Li}^{+}$-ion batteries is carbon in its different layered structures.

\subsection{Role of carbon material in batteries}

Li metal anodes with an organic electrolyte result in nonuniform formation of a passive film on the anode surface [20-22], which causes dendrite growth of Li metal. Longer charging-discharging cycles are one of the important requirements for making a commercially viable Li-ion battery. This problem is tackled by utilizing the electrochemical intercalation of $\mathrm{Li}$ in carbon. It produces a significant negative potential close to that of $\mathrm{Li}$, but this is less reactive and easily reversible [23].

Various kinds of carbon materials have been employed as anodes in various electrolytes for Li rechargeable batteries. Carbon offers advantages over other types of materials used in rechargeable batteries such as high operating voltage, longer life cycle and lack of "memory" effects [24-26]. The structural characteristics of carbon are believed to be the major factor that controls the performance of $\mathrm{Li}^{+}$-ion batteries. The intercalation of $\mathrm{Li}^{+}$ion with carbon depends upon many factors such as the preparative history, carbon precursor and structure. The variations in the average layer spacing and the voltage profile for the carbon with intercalating depend 
on the degree of graphitization [27]. Literature survey on carbon in battery development revealed that graphite is the most commonly used anode for $\mathrm{Li}^{+}$-ion secondary battery. Many studies employed graphite as an anode, which has theoretical capacity of $372 \mathrm{mAh} / \mathrm{g}$ based on the stoichiometry of Li carbon [28-34].

\subsection{Graphene materials for highly performing electrodes}

The widespread interest in graphene includes its potential as a suitable material for energy storage and particularly for $\mathrm{Li}^{+}$-ion batteries. Intrinsically, graphene is aimed at providing excellent performance based on a combination of physicochemical properties, its extremely high surface area of 2,630 $\mathrm{m}^{2} / \mathrm{g}$ [35], high electrical conductivity and chemical inertness [36].

Crystalline carbon nanomaterial, carbon nanotube [37, 38] and graphene had their expected applications in electrochemical energy storage. This was precisely envisioned for both $\mathrm{Li}^{+}$-ion and Li-sulfur batteries and supercapacitor devices [39]. Advantageously with respect to carbon nanotube, graphene is the basic unit of $\mathrm{sp}^{2}$ carbons (graphitic), which are the most conventionally/commonly used carbons for batteries (or other high surface area applications).

Production wise, the cost of using a certain graphene material could be compared with conventional and cost-efficient traditional macroscopic methods, based on topdown approach or on raw materials, typical chemical or metallurgical approaches to obtain graphite (and graphene-like materials) synthesis and cell-making methods. Examples of current trends and recent achievements include pyrolytic graphite from graphene oxide [40] and kish graphite [41], which are obtained from waste graphite flakes from steel production. Scalable recycling and reusing approach applied to these abundant raw materials will be cited in the following sections.

In the following section, a nonexhaustive collection of bottom-up methods, selected techniques for production of high-quality graphene materials as well as examples of graphene-decorated electrodes are described. For a comprehensive topic review on graphene synthesis, there exist a number of extended resources such as how to achieve specialized morphologies, particularly, those specifically useful/appropriate for EC energy storage [42]. Interestingly, some general vision and hints on using waste and recycled or recyclable carbon sources are included for the described methods. Besides, the quest for valorizing waste materials for energy storage is not new or exclusive for novel nanomaterials [43]. The use of hierarchical structures such as combining graphene with other materials, for example, oxides [44], is beyond the scope of this text. 
In summary, graphene is still considered to ultimately outperform existing solutions as it would provide improvements in terms of increased surface area (i.e., enabling higher capacity and also lighter devices), conductivity (faster charge-discharge and efficiency) and increased chemical and mechanical resistance. Relevant evaluation and benchmarking of graphene electrodes as electrochemical energy storage elements in affordable graphite materials, to critically assess their real potential and, eventually, quantify the advantages of graphene in operation that is needed in both energy and power density are carried out. The expected exponential increase in demand and performance of batteries, resulting from their use in electrified vehicles, requires advanced and sustainable solutions. Fundamental investigations on graphitic structure from waste material for electrochemical energy storage are focused on elucidating whether they provide unique features and advantages to affordable carbons, rather than being competitive to existing commercial solutions. Therefore, they are generally based on the "ideal" concept of graphene. High-quality graphene material, in contrast to common graphite/graphitic materials and low-quality graphene materials, can be defined as pure carbon, large crystal domain size and isolated films, that is, typically consisting of monolayer graphene or, eventually, bilayer or few layers' graphene. In fact, classification of graphene based on these three parameters has been established for proper reference in scientific papers and enabling some standards for industrial purposes, such as production [45]. Advantageously, laser power seems to provide a way to transform a variety of heterogeneous materials into two graphitic forms [46]. Similarly, one could envision that the resources potentially include waste materials.

Recently, attention has been drawn to use disordered carbon materials. It may store Li via a mechanism that is completely different from that associated with graphite. Additional studies indicate that Li insertion into an unorganized carbon loses the layer structure [47]. Variation in the polarization resistance with intercalation revealed the processes in various disordered carbons. It demonstrated the single-phase reactions with different stoichiometry of Li intercalation. Electrochemical intercalation of Li into carbons has been studied using mesophase pitch-based carbon fibers with different heat-treatment temperatures, coke [48] and graphite as anodes [27, 47, 49]. It has been found that the activation energy for the diffusion process decreases by increasing the degree of graphitization [27]. The studies also demonstrated that intercalation of Li with camphor-based carbon nanobeads stabilize the cell for 10-20 days [50, 51]. The reversible $\mathrm{Li}^{+}$-ion intercalation capacity was found to be $45-61 \%$ of that obtained with graphite [51]. Researchers also reported the result of Li intercalation by carbon nanomaterial obtained from the pyrolysis of biochar such as tealeaves [52].

Research on Li diffusion in carbon is of both theoretical and practical interest. The process was largely studied in connection with the development of $\mathrm{Li}^{+}$-ion batteries, whose negative electrode is based on graphite or some other carbon material [27, 53-61]. In some works, Li diffusion was investigated during the reverse process, 
that is, the anodic deintercalation [47, 62-66]. A complex impedance model for spherical particles was used to determine the $\mathrm{Li}^{+}$-ion diffusion coefficient in graphite as a function of the state of charge and temperature [67]. Practically, in all cases, studies were concentrated on the diffusion of $\mathrm{Li}$, which was electrochemically incorporated during cathodic polarization of a carbon material in an aprotic electrolyte [68].

However, carbon pyrolysis at low temperature shows attractive behavior as their theoretical capacity exceeds that of graphite as anode material [52, 69-75]. This observation indicates that there may be some other different mechanisms operating in these carbons in terms of Li intercalation. However, the density of lowtemperature carbon is lower than that of graphite [76]. Therefore, the capacity of low-temperature carbon should be large enough to compensate for its smaller density. The capacity of an anode for $\mathrm{Li}^{+}$-ion battery depends on the amount of carbon that can be placed within the limited volume of a typical battery container. Carbon obtained from the same precursor at different temperatures has different structural orientation. Therefore, trial and error is often needed to establish a suitable preparation method for optimizing the properties of carbon [77, 78]. Many researchers studied the relation between the properties of carbon and its electrochemical characteristics relevant to $\mathrm{Li}^{+}$-ion rechargeable [79-85].

As for the source of atomic carbon, methane is the commonly used gas as its decomposition products are the simplest. The reuse of greenhouse gases such as the very methane for graphene production would follow automatically. Similarly, green approach is also aimed at reusing carbon dioxide [86], yet it is more complex in terms of chemistry and efficiency of the reaction. Likewise, a number of additional works have actually been reported for the (re)use of greener carbon sources, which include molecules or polymers [87], as well as various recycled waste materials, such as plastics but also organic materials or industrial coal (Figure 6.1) [88-90].

In this study, we examined the effects of carbonization atmosphere on the charge-discharge characteristics of carbon from waste source as an anode for $\mathrm{a}^{+}{ }^{+}$ion rechargeable battery. This work targeted the "green" approach for energy storage. The carbonaceous materials such as carbon nanowalls (CNWs) and carbon fiber sheet used in this study were made from different precursors such as organic waste (methane) and polymer waste [nanoscale microfibrillated cellulose (NMFC)].

\subsection{Vertically oriented micro-mesoporous CNWs}

Graphene materials obtained by chemical vapor deposition (CVD) present several limitations for EC energy storage. First, morphologically the effective graphene surface could be reduced up to half of its theoretical value as CVD-obtained graphene is bonded/stuck onto the metal substrate. Besides, the high temperature used in CVD is not desirable to obtain wrinkled or crumbled carbon, especially if power 

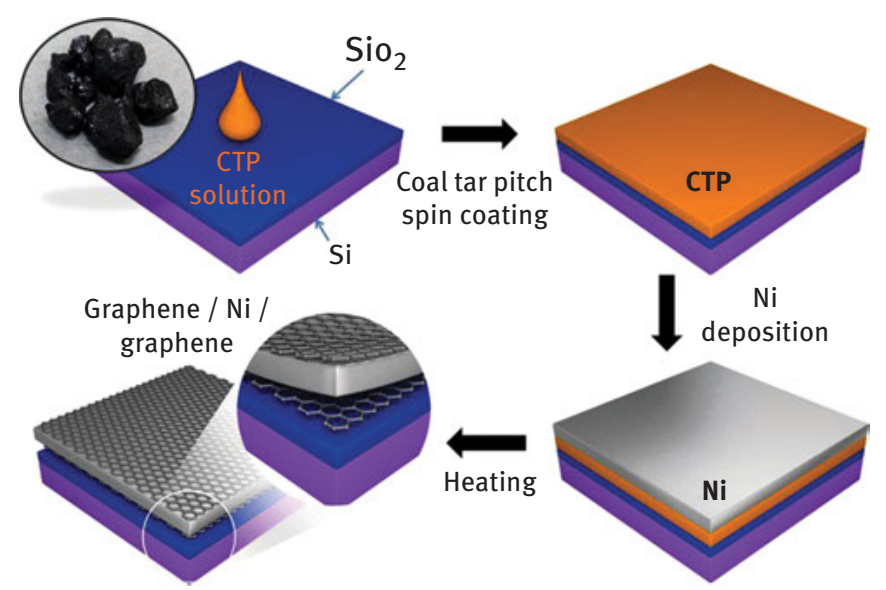

Figure 6.1: Graphene films are converted from coal tar pitch on the top and bottom surface of $\mathrm{Ni}$ layer [90]. (Image courtesy: https://www.nature.com/articles/srep16710/figures/1)

consumption reduction is aimed, but also for process compatibility, with any substrate such as plastics. Apart from providing better volume-area ratio, an increase in charge storage capacity is expected from the large amount of graphene flake edges to the electrolyte. Consequently, alternatives of producing porous or microstructured carbon materials, ideally based on scalable techniques, have been studied [91].

As an analogy with CNTs, this is the case of using physically assisted CVD systems, such as fitted with radiofrequency and microwave (MW) sources. In particular, for certain solid sources, the reactivity of physically assisted CVD such as based on the use of a powerful MW field may restrict the growth process to be operated in conditions of relatively low pressure. For instrument and operator's safety in the presence of chemical elements (carbon source), many systems and synthesis principles do make use of hydrogen as a carries gas to avoid oxygen contamination. With the plasma systems, the reuse of methane and other recycled carbon sources may be possible to be applied. Although the compatibility of recycled carbon sources could be more difficult in general, it has actually been achieved [92]. Yet, more examples can be found in the literature [93].

Figure 6.2 provides the image of CNWs deposited on $\mathrm{Cu}$ substrate, which has the possibility of being used as anode for $\mathrm{Li}^{+}$-ion batteries. Owing to the orientation and morphologies, obtained materials are typically referred in the literature with a variety of terms, including carbon nanosheets [94] or CNWs [95]. These graphene flakes or CNWs are randomly distributed, perpendicularly oriented to the substrate and/or curvy. Their dimensions are maximum of approximately 1-1.5 $\mu \mathrm{m}$ in height and 10-20 nm in thickness, which accounts for multilayered 

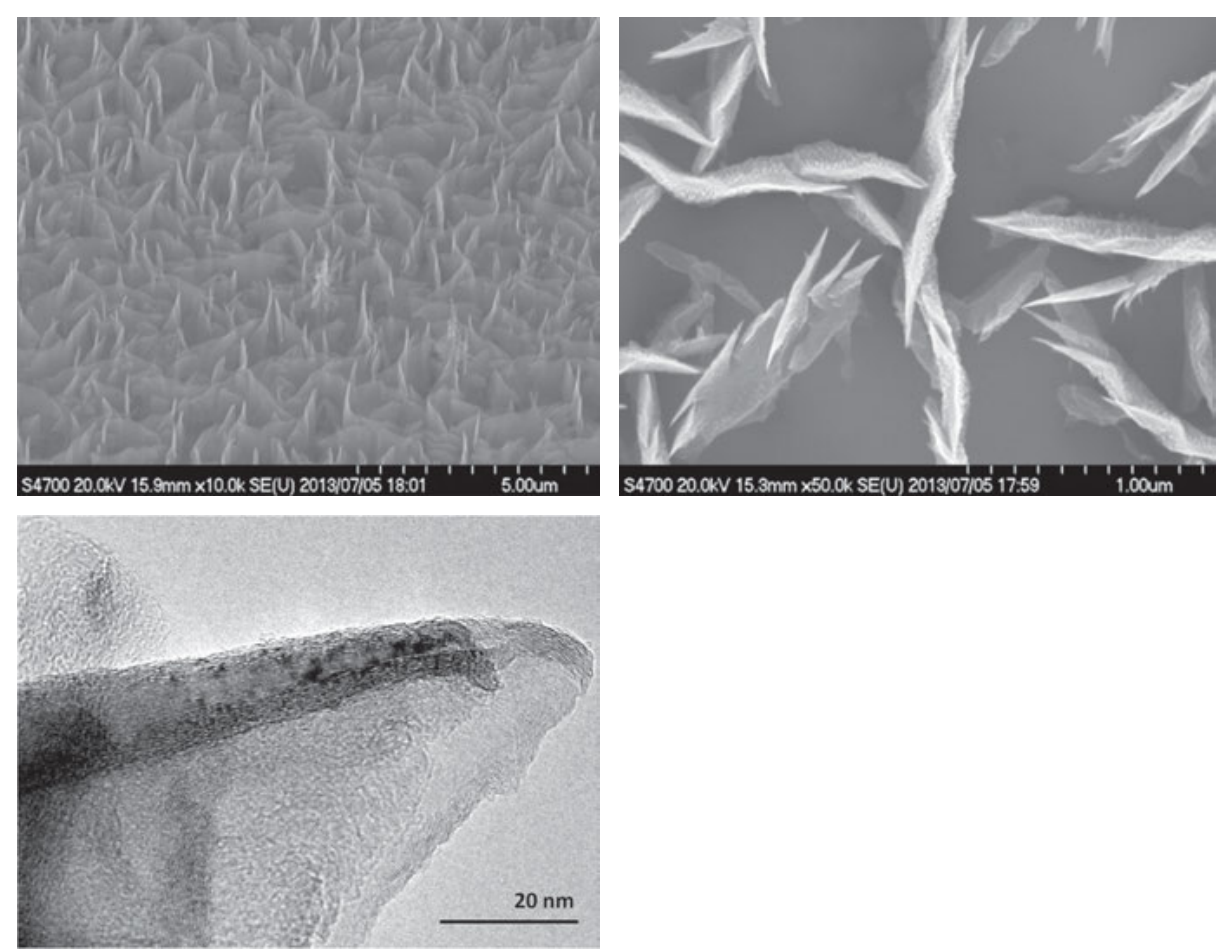

Figure 6.2: Microscopic images of CNWs deposited on Cu: (left and center) FESEM and (right) TEM image.

graphene, and are characterized by very small crystal size, in the order of nanometers. This is further confirmed with micro-Raman analysis.

The observed Raman spectra (Figure 6.3) is typical of a good quality graphitic material. Both first- and second-order Raman effects can be seen. First-order Raman peak is presented as a so-called G-peak around $1,580 \mathrm{~cm}^{-1}$. This peak is commonly observed in all graphitic materials being often the sharpest and intense one. It arises from the first Brillouin zone center of the graphene unit cell and it is due to the double degeneration of in-plane transverse optic $[96,97]$ and longitudinal optic modes [98, 99]. All other peaks are due to second-order Raman effects. The main peak belonging to this category is D-peak around $1,350 \mathrm{~cm}^{-1}$. This peak is normally associated with the disorder of the graphitic structure. The principal reasons for the presence of this peak are the combination of grain boundaries, vacancies and other structural defects. The D-peak is particularly intense and very sharp: this can be explained not mainly by the density defects but related to the particular orientation of CNWs, which are vertically aligned or oriented (mainly edges exposed to laser beam). This statement is further confirmed by looking at the $D+G$ peak. It does not show any abnormally great number of defects. In conclusion, D-peak intensity is 


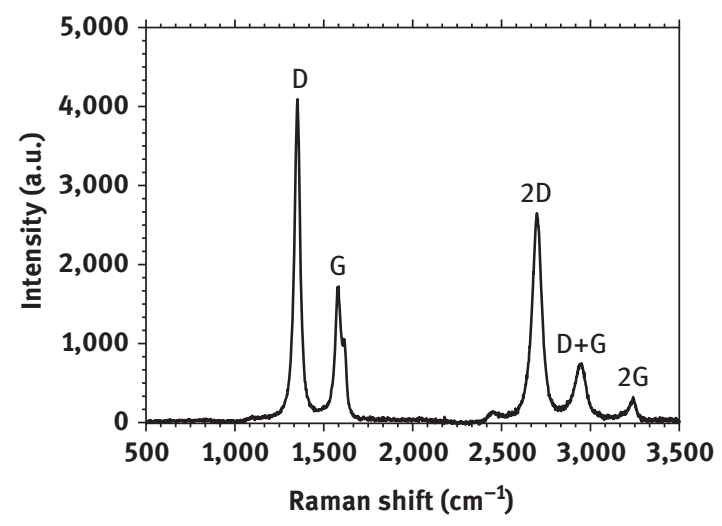

Figure 6.3: Raman analysis of CNWs. (Image courtesy by Electrochimica Acta (Elsevier) to reuse in a book under the copyright license number 4454750182186 )

correlated with the number of defects in the structure, while the full-width halfmaxima of D-peak is correlated with the grain size. The presence of a rightshouldered G-peak around 1,620 $\mathrm{cm}^{-1}$ is called second-order D'-peak which appears as a shoulder peak of G-peak. This peak is observed in some disordered graphitic carbon structures, including graphene, but cannot be seen in defect-free structure. Its intensity is usually lower as compared to the G-peak but becomes more important especially in CNW structure. Other second-order features are indicated by the remaining peaks named $2 \mathrm{D}, \mathrm{D}+\mathrm{G}, 2 \mathrm{G}$. The peak around $2,700 \mathrm{~cm}^{-1}$ is often called 2D. Generally, this peak fall around a zone of the Raman graph where the 2D Raman shift doubles the Raman shift of the D-peak [100, 101]. The origin of peaks is not related to the presence of defects or grain boundary. It arises from the interaction of two phonons. The peak is very intense, especially in planar structure like graphene, CNWs. The peak shape of Raman can give us information about the number of layers present in the structure [102]. The peak around 2,700 $\mathrm{cm}^{-1}$ observed here is $D+G$ peak, which is generally associated with the damaged graphene. It is less evident or almost absent in high-quality and defect-free carbon structure [103]. The peak around $3,240 \mathrm{~cm}^{-1}$ is sometimes called $2 \mathrm{G}$ and is present in both planar (graphene, graphite, CNWs) and nonplanar (CNT) structures [104].

\subsection{Growth of CNWs}

Vertically arranged graphene materials, arrays of CNWs, can be grown onto aspurchased flexible metal polycrystalline $\mathrm{Cu}$ foil. It is directly tested as anode in $\mathrm{Li}^{+}$-ion batteries without any prior treatment [70, 105]. A commercial MW plasma-enhanced 
CVD technique (CVD-CN-100 from Ulvac, Japan Ltd.) [106-108] is used for the growth of CNWs. The whole process and growth conditions typically consist of, first, exposure of $\mathrm{Cu}$ foil to a hydrogen $\left(\mathrm{H}_{2}\right)$ flux; then, methane $\left(\mathrm{CH}_{4}\right)$ as a reaction gas is introduced in combination with $\mathrm{H}_{2}\left(\mathrm{H}_{2}: \mathrm{CH}_{4}\right)$ with the ratio of $20: 20 \mathrm{sccm}$. At growth stage, bias voltage of $200 \mathrm{~V}$ is applied. The whole process is done at a constant pressure of 1.5 mTorr pressure. In the process, hydrocarbon gas decomposes into graphitic carbon. The process needs to be catalyzed and is therefore applied on affordable $\mathrm{Cu}$-metal surface, which provides a better control on the number of layers with electrochemically active surface. Figure 6.4 shows the charge-discharge cycling of CNWs on $\mathrm{Cu}$ at different current rates. The behavior of current is slightly different from the standard behavior of carbon. This may be due to the presence of disordered carbon in the CNW deposits (as learnt by Raman spectroscopy). However, one of the highlights of the material is that even if the current rate is increased to higher orders, the capacity is not dropping down.

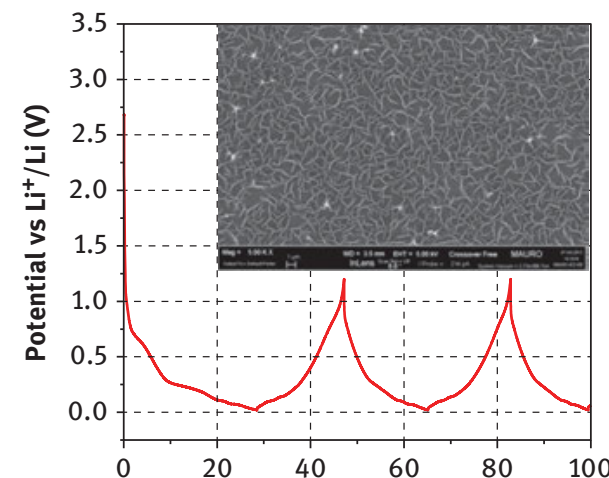

(a)

Time (h)

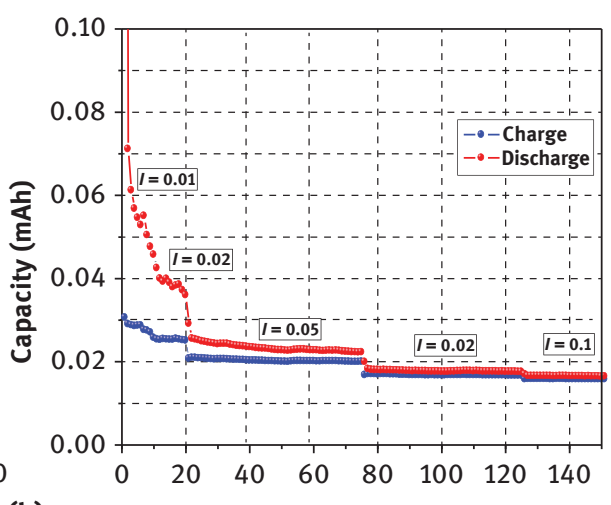

(b)

Cycle number

Figure 6.4: (a) Graph showing the galvanostatic charge/discharge curves of CNWs deposited on Cu: inset - morphological characterization of the nanostructured carbons deposited on Cu by FESEM (ZEISS Supra 40); (b) capacity versus number of cycles in a cell Li/electrolyte/CNW-Cu at room temperature. (Image courtesy by Electrochimica Acta(Elsevier) to reuse in a book under the copyright license number 4454750182186)

\subsection{Carbonized cellulose paper}

Use of paper in our everyday life has turned out to be an original answer to the demand of eco-friendly, flexible, lightweight and cost-effective materials for electronics $[108,109]$ and energy-storage devices $[110,111]$. There are promising reports on paper/cellulose-based composite electrodes for supercapacitors and Li batteries 
$[112,113]$; the rough and porous surface of paper has turned out to be a great advantage, where both high surface area and electrolyte absorption are in demand. Recyclability and biodegradability are significant benefits, considering that cost of waste management and impact on the environment could be considerably low. It has been proven by Liu et al. [109] that paper printed circuit boards have about two orders of magnitude less impact on the environment than the ordinary printed ones.

The work on this material has demonstrated the feasibility of manufacturing graphite-based negative electrodes on a pilot-line exploiting microfibrillated cellulose as binder, through the spray-coating method, and the use of water-based papermaking technologies for large-scale production of Li batteries [114]. Beneventi et al. have successfully assembled a flexible, truly solid $\mathrm{Li}^{+}$-ion cell based on selfstanding electrodes manufactured using conducting paper as substrate. This approach makes use of a carbonization step of the nanocellulose-binded electrodes at high temperature to obtain conducting carbon nanofiber binder concurrently removing water and impurities, so that no successive drying step was necessary, thus making it more cost-effective in terms of energy and time. An NMFC-reinforced polymeric membrane which was activated by incorporating a freshly prepared room temperature ionic liquid-based green and safe electrolyte solution was used, and the resulting truly solid system assembled in a "pouch cell" envelop demonstrated a remarkably stable cycling behavior upon prolonged cycling at ambient temperature even at elevated current rates as well as in bent configuration. It was also noted that all cell components could be easily recovered using common waterbased recycling procedures used in paper mill. The waste was minimal; the process was of low cost and low energy demanding, which led to the worldwide sustainable Li-based battery use and recovery.

\subsection{Preparation of self-standing electrodes}

Figure 6.5 demonstrates the different processes involved in obtaining pyrolyzed nanocellulose-binded electrodes, which are then used to assemble the solid polymeric $\mathrm{Li}^{+}$-ion cell. The anode slurry was made of graphite powder (GP), carbon black (CB), NMFC, carboxy methyl cellulose (CMC) and alum. The cathode slurry was composed of lithium iron phosphate $\left(\mathrm{LiFePO}_{4}\right) /$ carbon, $\mathrm{CB}, \mathrm{NMFC}, \mathrm{CMC}$ and alum. Both the slurries, having a dry solid content ranging between 25 and 15 wt.\%, were prepared by dissolving CMC in the aqueous NMFC slurry, followed by the addition of $\mathrm{CB}$.

A commercial airless spray system (Wagner, Project Pro 119) was used to spray the anode slurry on both sheets and on other substrates (i.e., smooth polyester films and copy paper). An aqueous suspension of carbonized NMFC (2 wt.\%) was 


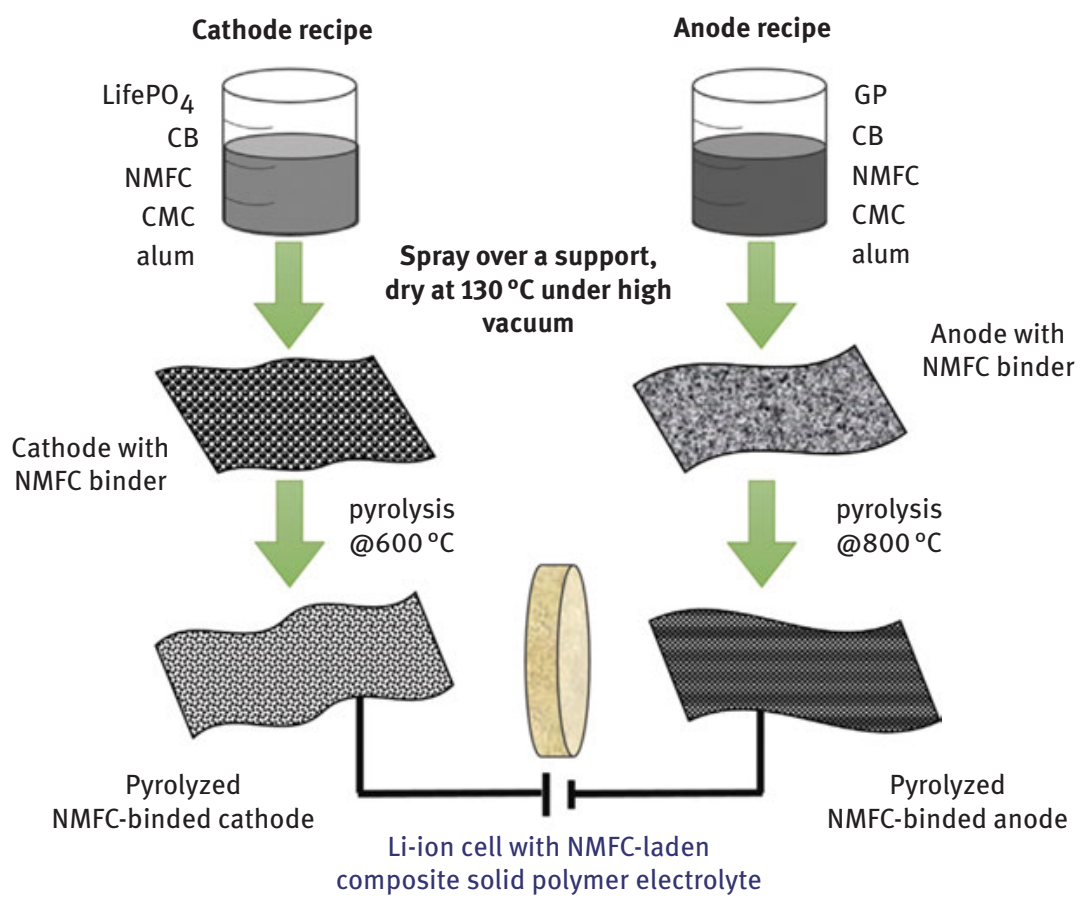

Figure 6.5: Different phases of the process involved in obtaining pyrolyzed nanocellulose-binded electrodes, which are then used to assemble the solid polymeric $\mathrm{Li}^{+}$-ion cell. (Image courtesy by Carbon (Elsevier) to reuse in a book under the copyright license number 4454160899455)

prepared for reinforcing the polymer electrolyte and also the same was used as a binder for retaining the active materials within the electrode films (Figure 6.6).

\subsection{Pyrolysis of cellulose paper}

Pyrolysis method [115] is adopted for carbonization of waste NMFC. This involves the pyrolysis of self-standing anode and cathode samples at 800 and $600{ }^{\circ} \mathrm{C}$, respectively. To avoid thermal degradation of the $\mathrm{LiFePO}_{4}$ active material, lower pyrolysis temperature was applied to the cathode material. The pyrolysis chamber is normally flushed with argon inert gas to avoid oxygen traces. The furnace is heated with $10{ }^{\circ} \mathrm{C} / \mathrm{min}$. Pyrolysis is carried out for $30 \mathrm{~min}$ after achieving the required temperature. These steps ensured the completion of the carbonization procedure. Figure 6.7 shows the different forms of an NMFC sheet that has undergone pyrolysis. The pyrolysis method is normally followed by the cooling of the furnace to room temperature to recover the carbonized materials [69]. 

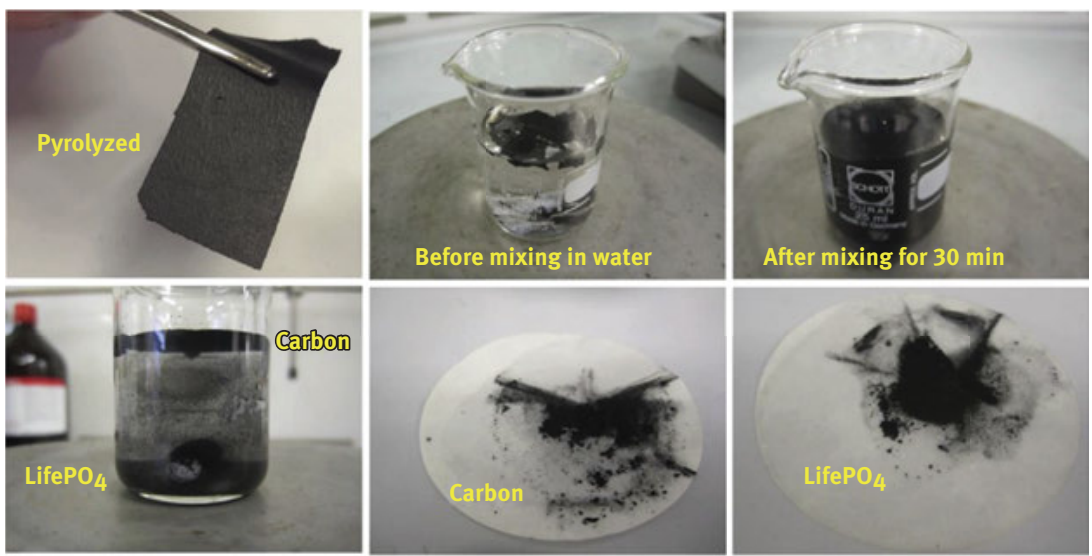

Figure 6.6: Different steps illustrating the facile recovery of pyrolyzed nanocellulose-binded electrode materials by exploiting the standard water-based recycling procedure used in paper industries. (Image courtesy by Carbon (Elsevier) to reuse in a book under the copyright license number 4454160899455)
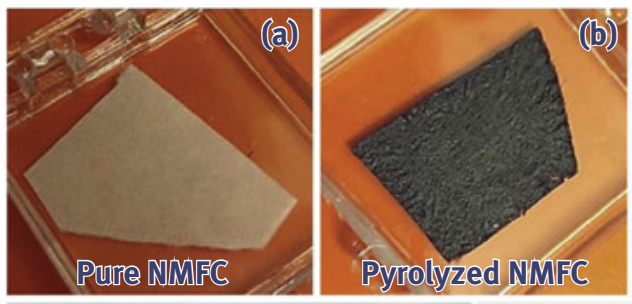

(d)

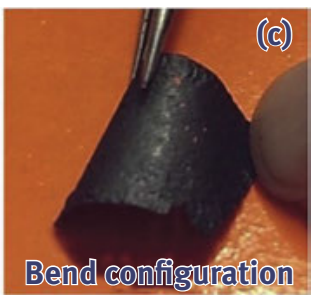

(e)
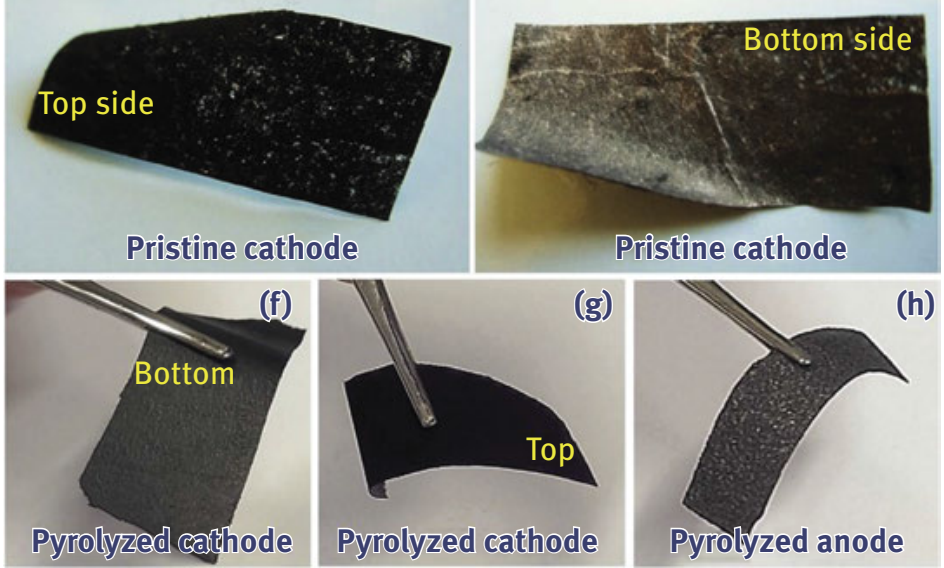

(g)

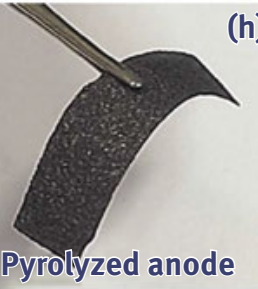

Figure 6.7: Self-standing ability of (a) pristine NMFC paper, (b) pyrolyzed NMFC paper, (c) pyrolyzed NMFC paper in its bend configuration, (d) representative nanocellulose-binded $\mathrm{LiFePO}_{4}$-based cathode in its top and (e) bottom side views, (f) pyrolyzed $\mathrm{LiFePO}_{4}$-based cathode in its bottom and (g) top side views, (h) pyrolyzed GP-based anode. (Image courtesy by Carbon (Elsevier) to reuse in a book under the copyright license number 4454160899455) 


\subsection{Analysis of pyrolyzed cellulose paper}

Figures 6.8 and 6.9 shows the FESEM images of GP-based anode pyrolyzed at $800{ }^{\circ} \mathrm{C}$ and $\mathrm{LiFePO}_{4}$-based cathode pyrolyzed at $600^{\circ} \mathrm{C}$. The structure of the carbonized electrode (carbonized anode) is more accessible with respect to the pristine spraydeposited paper electrodes, and the presence of both $\mathrm{LiFePO}_{4}$ and $\mathrm{CB}$ particles is well evidenced. The carbonized cellulose fiber network successfully binds the electrode components effectively, maintaining the preburning structure, despite slight shrinkage. It was observed that $\mathrm{LiFePO}_{4}$ particles perfectly maintained their characteristics after heat treatment without suffering any kind of modification (Figure 6.9d). The fundamental triphasic system composed of the active material grain $\left(\mathrm{LiFePO}_{4}\right.$ particle), the electronic conductivity enhancer ( $\mathrm{CB}$ spherical particle, locally enhancing the electronic conductivity of $\mathrm{LiFePO}_{4}$ ) and the binder (electronic conductive carbonized cellulose fiber, which in turn also ameliorates the electronic conductivity of the system) was still present as highlighted by the yellow circle.
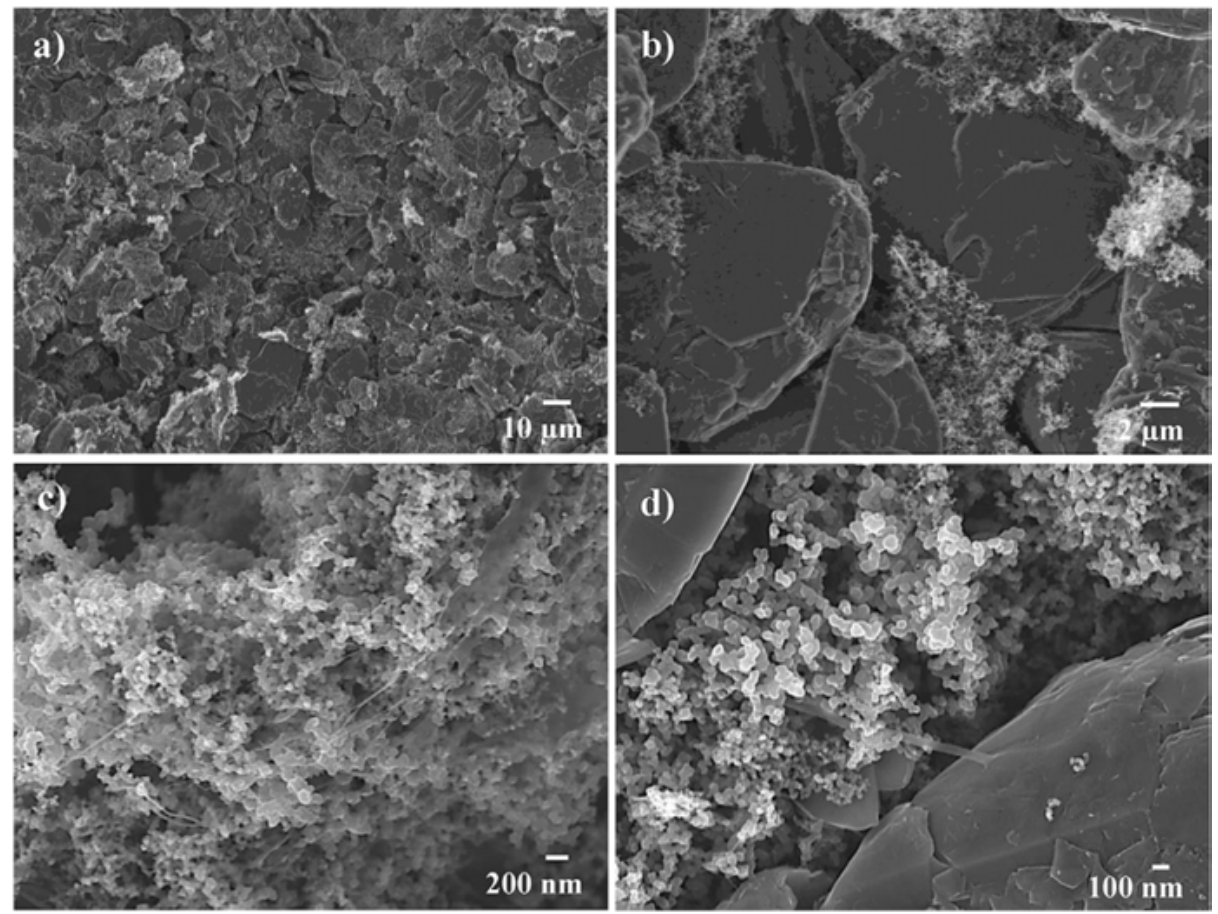

Figure 6.8: FESEM at different magnifications of GP anode pyrolyzed at $800^{\circ} \mathrm{C}$. (Image courtesy by Carbon (Elsevier) to reuse in a book under the copyright license number 4454160899455 ) 

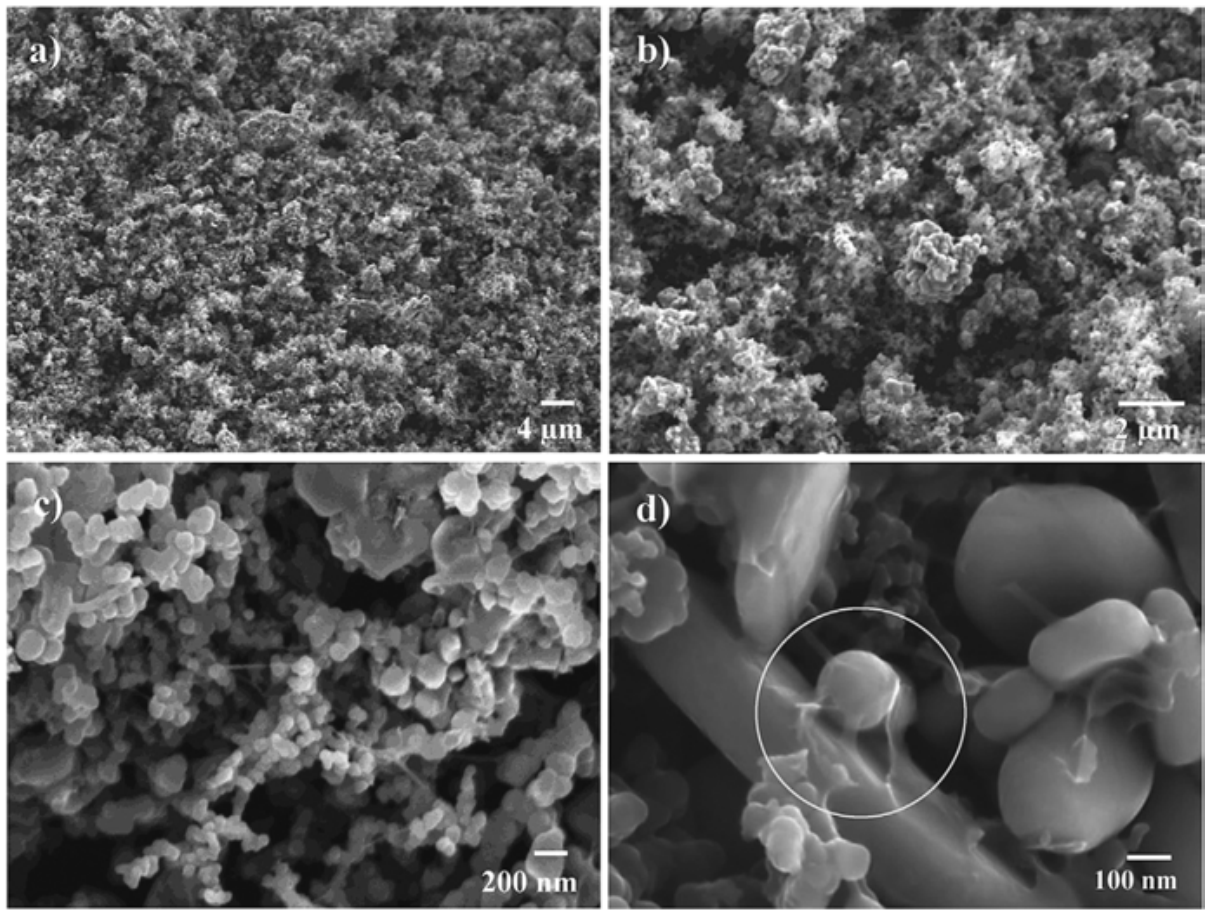

Figure 6.9: $\mathrm{FESEM}$ at different magnifications of $\mathrm{LiFePO}_{4}$ cathode pyrolyzed at $600{ }^{\circ} \mathrm{C}$. (Image courtesy by Carbon (Elsevier) to reuse in a book under the copyright license number 4454160899455)

Figure 6.10 shows the Raman spectrum of GP-based anode, $\mathrm{LiFePO}_{4}$-based cathode and NMFC paper. A-800-TS shows a good separation and sharp D, G and $\mathrm{G}_{0}$ peaks when compared with A-800-BS. It evidences that the carbon material in sample A-800-TS is better graphitized than that of A-800-BS. Raman analysis of top rough (C-600-TS) and bottom smooth (C-600-BS) surfaces of the $\mathrm{LiFePO}_{4}$-based cathode shows different behavior (Figure 6.10c and d). Intensity ratios shown in Figure 6.10f indicate that C-600-TS has lower graphitized matrix as compared to C-600-BS. The Raman spectrum of pyrolyzed NMFC paper (Figure 6.10e) shows no peak intensity and positioning variation on either side of the paper due to the uniform characteristics of both the surfaces. In general, the Raman analysis of pyrolyzed NMFC paper shows similar graphitized structure as that of C-600-BS. It can be stated that A-800TS and C-800-TS have lower degrees of graphitization after analyzing the Raman spectra. Raman analysis also confirmed that the temperature variation did not reflect on the variation of graphitization of the sample. Raman spectroscopy by itself does not provide a complete picture of carbon quality. 

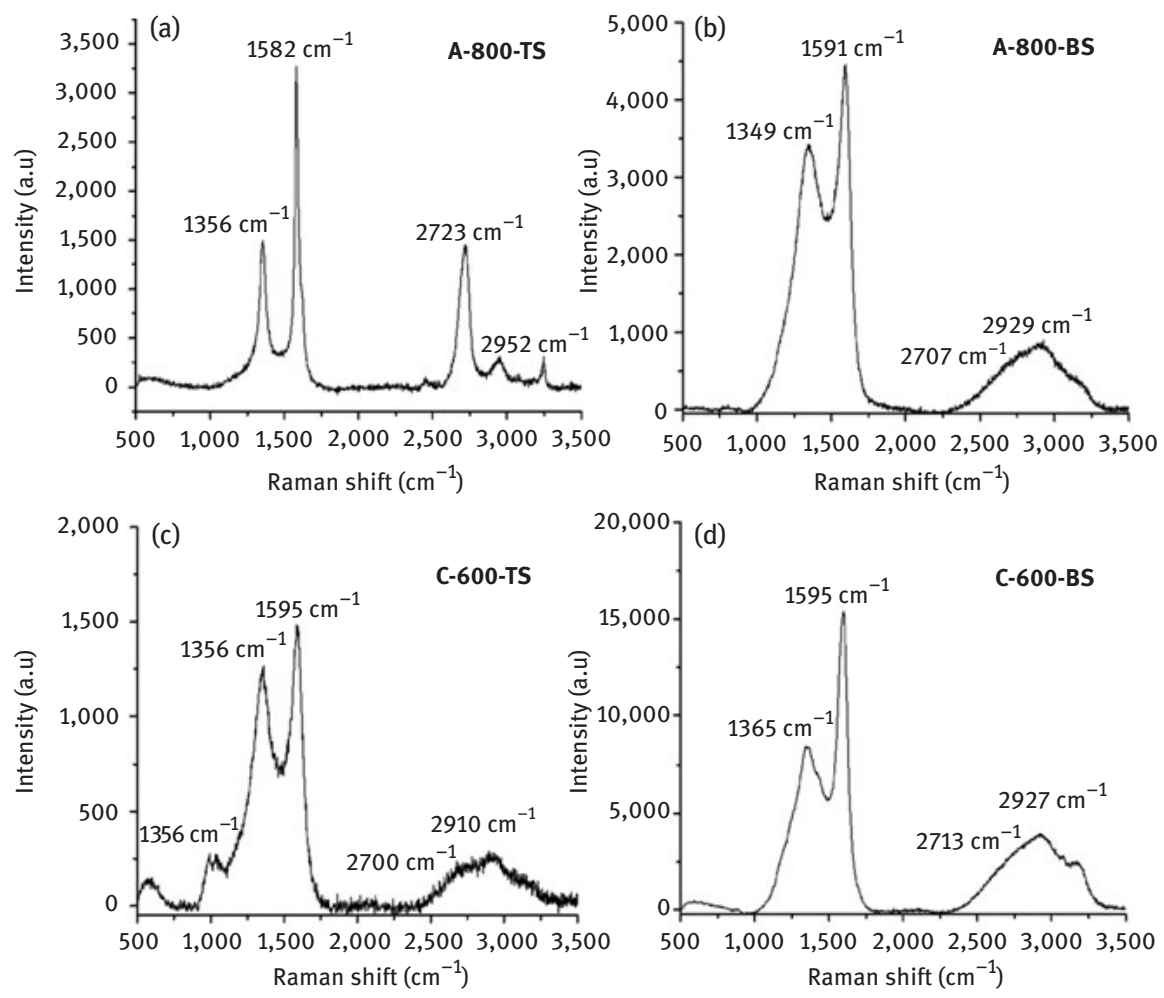

(d)
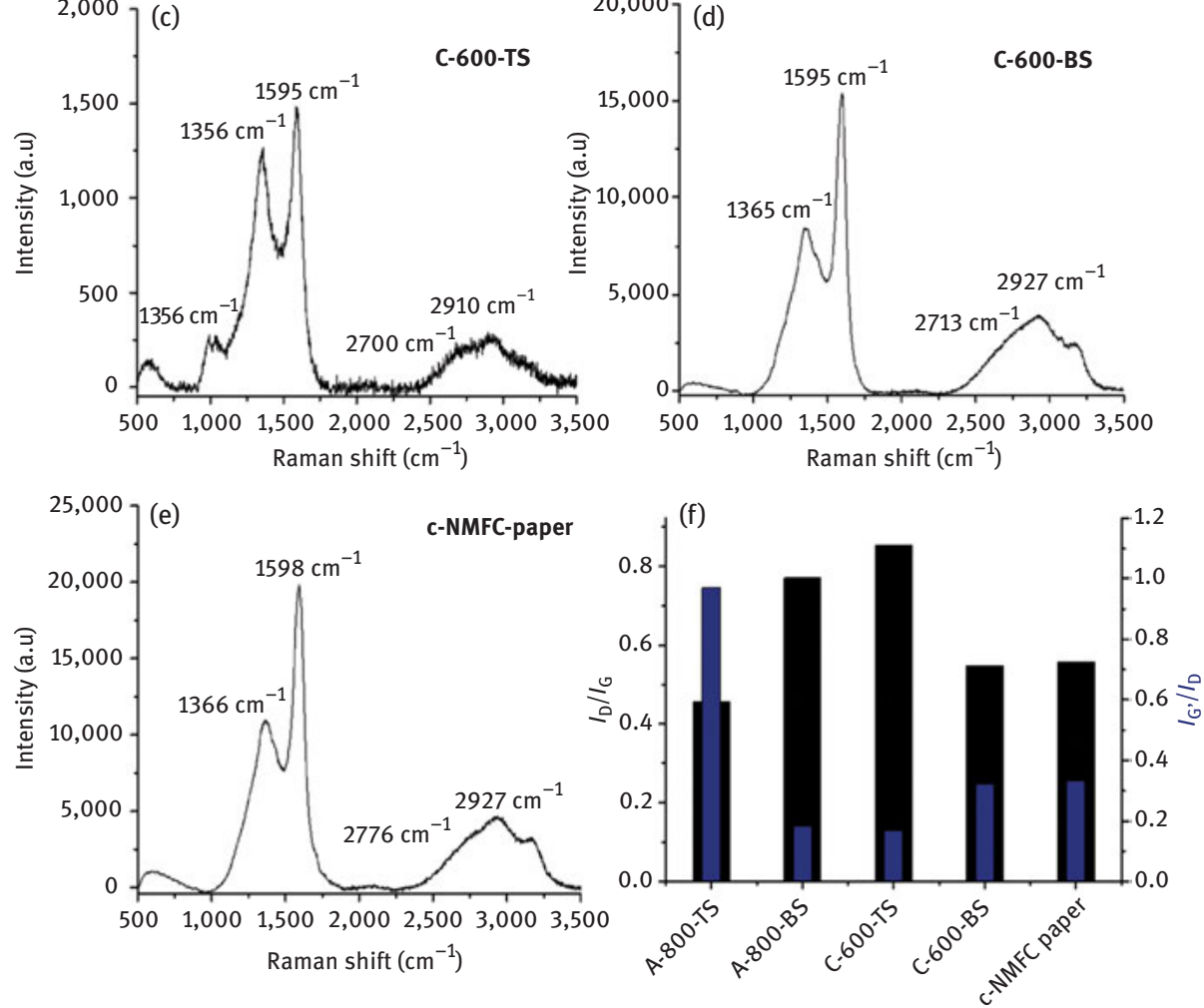

Figure 6.10: Raman spectra of (a) GP-based anode pyrolyzed at $800{ }^{\circ} \mathrm{C}$ analyzed on top and (b) bottom surfaces, (c) $\mathrm{LiFePO}_{4}$-based cathode pyrolyzed at $600{ }^{\circ} \mathrm{C}$ analyzed on top and (d) bottom surfaces, (e) NMFC paper carbonized at $600{ }^{\circ} \mathrm{C}$. (f) Samples versus $I_{\mathrm{D}} / I_{\mathrm{G}}$ and $I_{\mathrm{G}}, / I_{\mathrm{D}}$ ratios. (Image courtesy by Carbon (Elsevier) to reuse in a book under the copyright license number 4454160899455) 

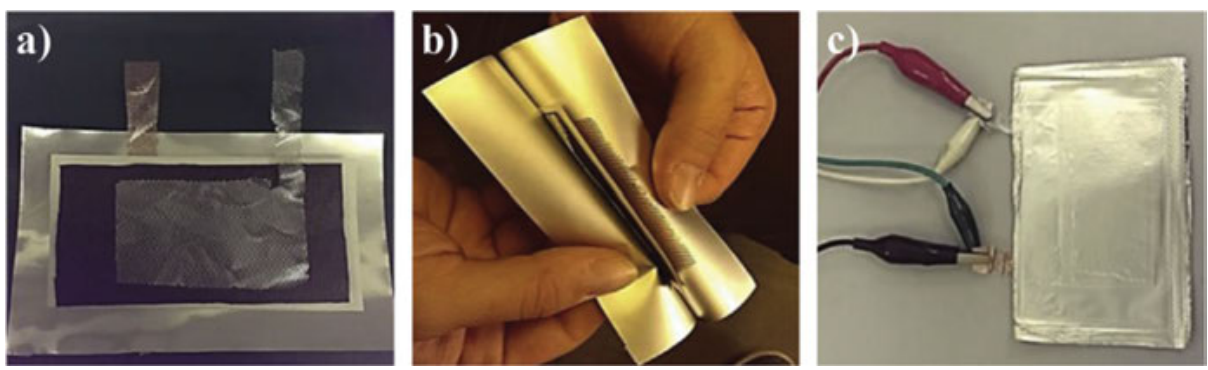

Figure 6.11: Different assembly stages of an all-paper-based solid polymer cell in pouch configuration: (a) assembly of the electrodes on the current collector grids, (b) packing followed by sealing, (c) final $\mathrm{Li}^{+}$-ion cell connected to the instrument for testing. (Image courtesy by Carbon (Elsevier) to reuse in a book under the copyright license number 4454160899455)

Figure 6.11 provides the different assembly stages of an all-paper-based solid polymer cell in pouch configuration. The composite polymer electrolyte is sandwiched between the carbonized nanocellulose-binded $\mathrm{LiFePO}_{4}$-based cathode and graphite-based anode paper electrodes and housed in a "pouch cell" envelop with $\mathrm{Al}$ and $\mathrm{Cu}$ grid current collectors (for cathode and anode, respectively). Different phases of the assembly are shown in Figure 6.11a-c. The cell is kept for ambient temperature galvanostatic charge/discharge cycling at various current rates.

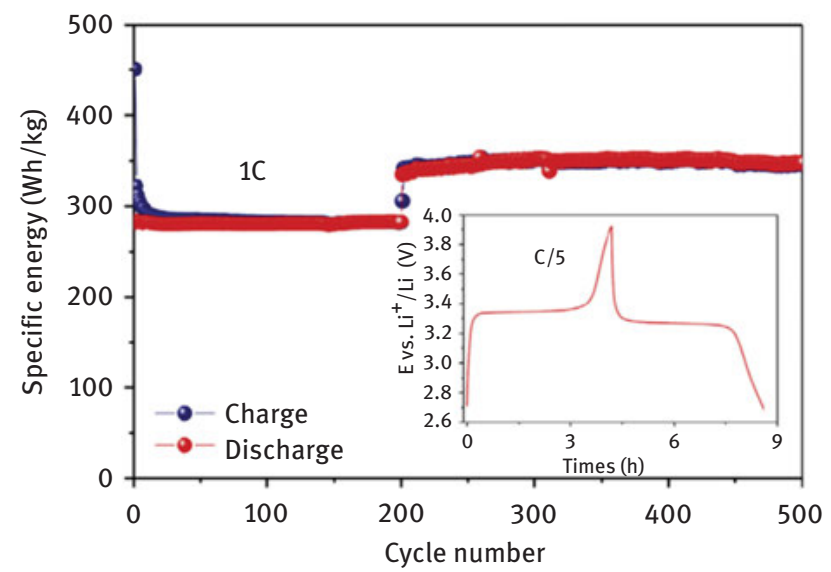

Figure 6.12: Current charge/discharge cycling behavior in terms of specific energy versus cycle number at different current regimes and charge and discharge potential versus time profiles extracted from the 400th cycle at C/5 rate. (Image courtesy by Carbon (Elsevier) to reuse in a book under the copyright license number 4454160899455) 
Figure 6.12 provides the electrochemical response of the $\mathrm{Li}^{+}$-ion polymer cell in terms of specific energy (Wh/kg calculated on the weight of the active cell components excluding current collectors and packaging) versus cycle number at different rates. The potential versus time profiles (400th constant current charge and discharge profiles at $\mathrm{C} / 5$ current rate) are very well consistent with the potential trend of the corresponding cell with natural cellulose bonded electrodes and liquid electrolyte [116]. The potential drop between charge and discharge plateaus was found to be limited, which accounts for low internal resistance, thus good electrode/electrolyte interface. The cell showed good rate capability and high coulombic efficiency approaching 100\%. Specific energy values were found to be definitely interesting for a solid polymeric device, approaching $300 \mathrm{Wh} / \mathrm{kg}$ at $1 \mathrm{C}$ and even exceeding $350 \mathrm{Wh} / \mathrm{kg}$ when reducing the current rate to C/5. Even more important, the cycling response is maintained steady for at least 500 cycles. This observation is definitely remarkable for a solid polymeric device. The exceptional capacity retention indicates that no contact loss occurred between the active material particles. The interface between active material particles and pyrolyzed nanocellulose binder remains intact even after over 500 charge/discharge cycles.

Figure 6.13 provides the electrochemical stability window of the composite polymer electrolyte evaluated by linear sweep voltammetry. It was found to exceed $4.6 \mathrm{~V}$ versus $\mathrm{Li}^{+} / \mathrm{Li}$ in the anodic region. The Li plating/stripping indicates an overall good cathodic electrochemical stability, which is evident at around $0 \mathrm{~V}$ versus $\mathrm{Li}^{+} / \mathrm{Li}$.

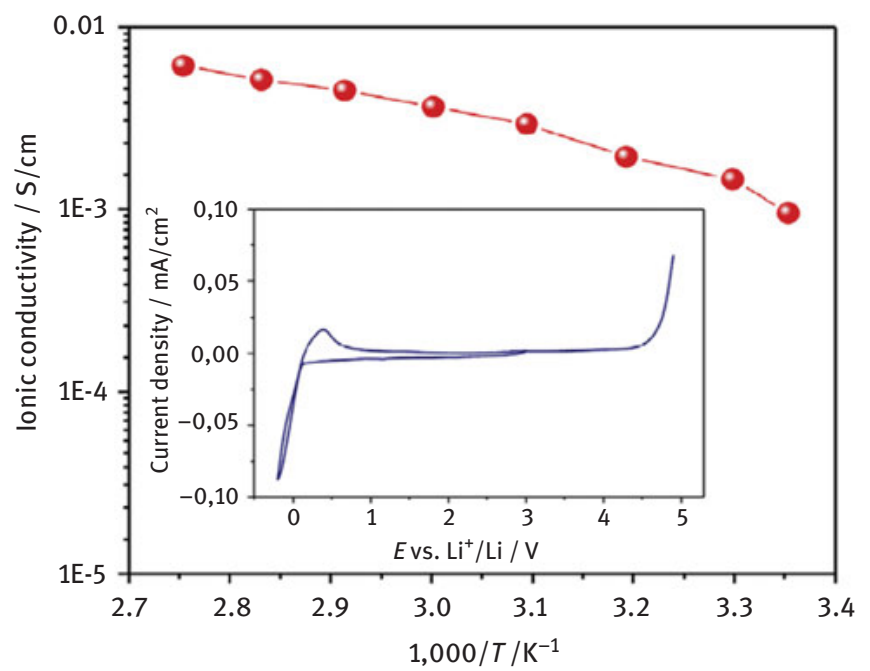

Figure 6.13: Arrhenius plot showing the ionic conductivity versus temperature; inset: electrochemical stability window of the polymer electrolyte. (Image courtesy by Carbon (Elsevier) to reuse in a book under the copyright license number 4454160899455) 

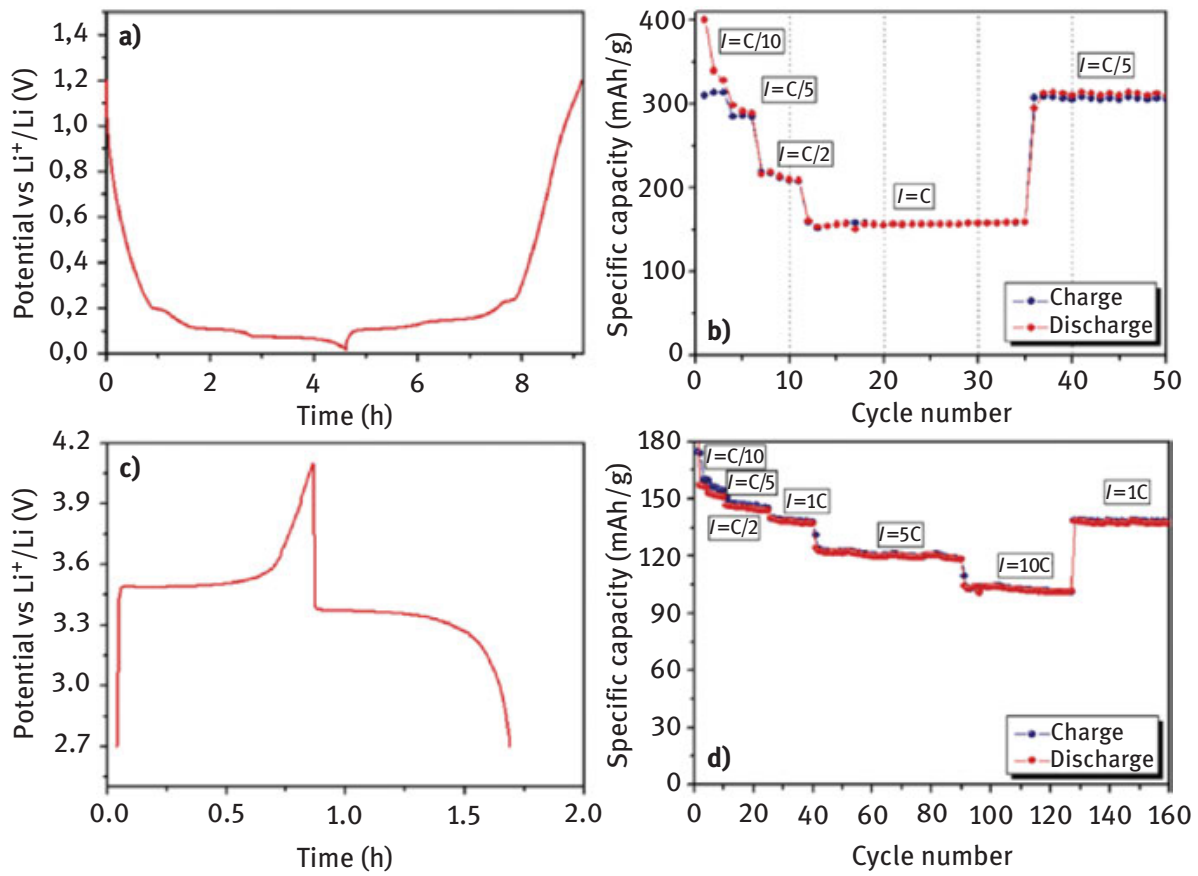

Figure 6.14: Ambient temperature electrochemical characterization of the carbonized electrodes in Li metal cell with standard liquid electrolyte: (a) potential versus time plot of a GP-based anode pyrolyzed at $800^{\circ} \mathrm{C}$ showing typical charge and discharge profiles at $\mathrm{C} / 5$; (b) specific capacity versus cycle number plot of the same anode at different discharge/charge current regimes; (c) potential versus time plot of a $\mathrm{LiFePO}_{4}$-based cathode pyrolyzed at $600{ }^{\circ} \mathrm{C}$ showing charge and discharge profiles at 1C; (d) specific capacity versus cycle number plot of the same cathode at different charge/discharge current regimes. (Image courtesy by Carbon (Elsevier) to reuse in a book under the copyright license number 4454160899455$)$

Figure 6.14 provides the potential versus time plot of the carbonized GP-based anode. Figure 6.14a clearly reflects the characteristics of the electrode active material. It shows the typical discharge (intercalation of $\mathrm{Li}^{+}$ions) and charge (deintercalation of $\mathrm{Li}^{+}$ions) profiles expected for a highly crystalline graphite material, where the different insertion steps toward the so-called stage-1 Li-graphite intercalation compound, that is $\mathrm{LiC}_{6}$, are clearly visible [117]. From the analysis shown in Figure 6.14b, the irreversible capacity loss during the first cycle can be attributed to the expected side reactions with the components of the electrolyte (solid electrolyte interface layer formation). Typically, organic solvent molecules and salt anions are reduced on the active material's surface. Thus, forming insoluble Li salt that precipitates to form a passivating film. This is helpful in preventing further reaction between components of the electrolyte and graphite active material [118]. 
The reversible specific capacity obtained at low $\mathrm{C} / 10$ rate is close to the theoretical value for graphite, reflecting the practical specific capacity of the commercial material used. This can be explained by the fact that the carbon obtained upon cellulose pyrolysis also takes part in the electrochemical process to a certain extent. After the initial cycles, the Coulombic efficiency rapidly increases to above $99 \%$. Subsequently, it remains highly stable throughout the cycles. This indicates that the formed surface film lasted intact and showed excellent reversible cycling after surface reactions were completed. At a relatively high current of $1 \mathrm{C}$, the anode can deliver a capacity of $150 \mathrm{mAh} / \mathrm{g}$, which is definitely higher if compared to the results obtained for the same pristine electrode reported by Beneventi et al. [114]. Thus, it can be summarized that the carbonization procedure at high temperature successfully enhances the electrochemical behavior of paper electrodes. This can be due to the improved electronic conductivity resulting from the presence of the carbonized network of fibers, which contributes to the overall electrode specific capacity. The performance of carbonized $\mathrm{LiFePO}_{4}$-based cathode in lab-scale Li cell was outstanding in terms of both overall specific capacity and rate capability (Figure $6.14 \mathrm{~d}$ ). The capacity obtained at low $\mathrm{C} / 10$ rate was around $160 \mathrm{mAh} / \mathrm{g}$, which is the specific capacity of the commercial material used. It is also interesting to note that after the specific carbonization procedure adopted, this kind of paperlike cathode is able to operate at very high 10C current regime, still providing specific capacity values exceeding $100 \mathrm{mAh} / \mathrm{g}$, thus allowing a higher power output of the final device. These results are difficult to be achieved by the corresponding "as-prepared" spray deposited $\mathrm{LiFePO}_{4}$-based electrodes as described by Zolin et al. [116]. This signifies the role of pyrolyzed nanocellulose fibers, which combine the functions of strong binder and conducting additive without negatively affecting cycling stability and rate performance [119]. It is worthy to note that this system does not show any performance decay; indeed, reducing the C-rate after more than 120 charge/discharge cycles completely restores the specific capacity, thus achieving excellent stability.

The overall observation concludes that the accomplishment of the " 12 principles of Green Chemistry" is a fundamental goal to be pursued by means of designing/optimizing environmentally "conscious" processes, materials and devices to reduce their environmental impact throughout all the phases of their life cycle, thus benefiting the economy, protecting people and achieving the real goal of a truly sustainable world. This goal can be achieved by exploiting carbonized nanocellulosic binders and water-based papermaking coupled with high-performing green composite polymer electrolyte.

Acknowledgments: This work was partially supported by grant 685844 (project MODCOMP) in the framework of European H2020 program. The authors thank Mr. Mauro Raimondo, Politecnico di Torino, for FESEM analysis of the samples. 


\section{References}

[1] Winter, M. and Brodd, R. J., What are batteries, fuel cells, and supercapacitors?. Chem. Rev 2004, 104, 10, 4245-4270, Oct.

[2] Linden, David, Handbook of Batteries, 3rd ed. McGraw-Hill, New York City, 1994.

[3] Lacks, D. J. and Mohan Sankaran, R., Contact electrification of insulating materials. J. Phys. D. Appl. Phys 2011, 44, 45, 453001, Nov.

[4] Khundkar, R., Malic, C., and Estela, C., Burned by a battery-coin short circuit: Old concept for a new burn, Burns 2010, 36, 1, e4-e5, Feb.

[5] Seroglou, F., Koumaras, P., and Tselfes, V., History of science and instructional design: The case of electromagnetism, Sci. Educ 1998. 7, 3, 261-280

[6] Whittingham, M. S., History, evolution, and future status of energy storage, Proc. IEEE 2012, 100, Special Centennial Issue, 1518-1534.

[7] George Blomgren, J. H., "Batteries, primary cells," in Kirk-Othmer Encyclopedia of Chemical Technology, Kirk-Othmer, Ed. Wiley, 2004, 880.

[8] Tarascon, J.-M. and Armand, M., Issues and challenges facing rechargeable lithium batteries, Nature 2001, 414, 359, Nov.

[9] M. S. W.-R. H. and Armand, M., Fast Ion Transport in Solids, W. Van Gool, Ed. New York, NY, United States, 1973, 645-665.

[10] Whittingham, M. S., Electrical energy storage and intercalation chemistry. Science (80-.) 1976 192, 42-44, 1126-1127.

[11] Murphy, D. W., Di Salvo, F. J., Carides, J. N., and Waszczak, J. V., Topochemical reactions of rutile related structures with lithium. Mater. Res. Bull 1978, 13, 12,1395-1402, Dec.

[12] Lazzari, M. and Scrosati, B., A cyclable lithium organic electrolyte cell based on two intercalation electrodes, J. Electrochem. Soc 1980, 127, 3, 773, Mar.

[13] Mizushima, K., Jones, P. C., Wiseman, P. J., and Goodenough, J. B., LixCoO2 (0. Mater. Res. Bull 1980, 15, 6, 783-789, Jun.

[14] Thackeray, M. M., David, W. I. F., Bruce, P. G., and Goodenough, J. B., Lithium insertion into manganese spinels. Mater. Res. Bull 1983, 18, 4, 461-472, Apr.

[15] Boehm, H. P., Setton, R., and Stumpp, E., Nomenclature and terminology of graphite intercalation compounds. Carbon N. Y 1986, 24, 2, 241-245, Jan.

[16] Armand, M., "Intercalation Electrodes," in Materials for Advanced Batteries, 1st ed., D. Murphy, Ed. New York: Springer US, 1980, 373.

[17] Brandt, K., Historical development of secondary lithium batteries. Solid State Ionics 1994, 69, 3-4, 173-183, Aug.

[18] Brandt, K., Herr, K., Hoge, D., DECHEMA Monogr 1993, 128, 279.

[19] Ohzuku, T., Iwakoshi, Y., and Sawai, K., Formation of lithium-graphite intercalation compounds in nonaqueous electrolytes and their application as a negative electrode for a lithium ion (Shuttlecock) cell. J. Electrochem. Soc 1993, 140, 9, 24-90, Sep.

[20] Koch, V. R., Specular lithium deposits from lithium hexafluoroarsenate/diethyl ether electrolytes, J. Electrochem. Soc 1982, 129, 1, 1.

[21] Daniel, C. and Besenhard, J. O., Handbook of Battery Materials, 2.Auflage. Wiley, 2011.

[22] Hirai, T., Effect of additives on lithium cycling efficiency, J. Electrochem. Soc, 1994, 141, 9, 2300.

[23] Flandrois, S. and Simon, B., Carbon materials for lithium-ion rechargeable batteries. Carbon N. Y 1999, 37, 2, 165-180.

[24] Z. Q. von S. U. Dahn JR, Sleigh AK, Shi H, Way BM, Weydanz WJ, Reimers JN, "Carbons and graphites as substitutes for the lithium anode in lithium batteries: New materials, 
developments and perspectivesitle," in Industrial chemistry library, 5th ed., P. G, Ed. London: Elsevier, 1994, 1-47.

[25] Agubra, Victor and Fergus, Jeffrey, Review lithium ion battery anode aging mechanisms. Materials (Basel) 2013, 6, 1310-1325.

[26] Kodama, T. and Sakaebe, H., Present status and future prospect for national project on lithium batteries. J. Power Sources 1999, 81-82, 144-149, Sep.

[27] Takami, N., Structural and kinetic characterization of lithium intercalation into carbon anodes for secondary lithium batteries. J. Electrochem. Soc 1995, 142, 2, 371.

[28] Wang, H., Ikeda, T., Fukuda, K., Yoshio, M., Effect of milling on the electrochemical performance of natural graphite as an anode material for lithium-ion battery," J. Power Sources 1999, 83, 1-2, 141-147, Oct.

[29] Liu, Z., Yu, A., and Lee, J. Y., Modifications of synthetic graphite for secondary lithium-ion battery applications. J. Power Sources 1999, 81-82, 187-191, Sep.

[30] McMillan, R., Slegr, H., Shu, Z.,Wang, W., Fluoroethylene carbonate electrolyte and its use in lithium ion batteries with graphite anodes. J. Power Sources 1999, 81-82, 20-26, Sep.

[31] Andersson, A. M., Edström, K., Thomas, J. O., Characterisation of the ambient and elevated temperature performance of a graphite electrode. J. Power Sources 1999, 81-82, 8-12, Sep.

[32] Yazami,R., Surface chemistry and lithium storage capability of the graphite-lithium electrode. Electrochim. Acta 1999, 45, 1-2, 87-97, Sep.

[33] W. X. and Dahn, J. R., Study of irreversible capacities for Li Insertion in hard and graphitic carbons. J. Electrochem. Soc 1997, 144, 4, 1195-1201.

[34] Y. I. and K. S. Ohzuku, Tsutomu, Formation of lithium-graphite intercalation compounds in nonaqueous electrolytes and their application as a negative electrode for a lithium ion (Shuttlecock) cell J. Electrochem. Soc 1993, 140, 9, 2490-2498.

[35] Geim, A. K. and Novoselov, K. S., The rise of graphene," Nat. Mater 2007, 6, 3, 183-191, Mar.

[36] Han, J. et al., Engineering graphenes from the nano- to the macroscale for electrochemical energy storage. Electrochem. Energy Rev 2018, 1, 2, 139-168.

[37] Niu, C., Sichel, E. K., Hoch, R., Moy, D., Tennent, H., High power electrochemical capacitors based on carbon nanotube electrodes. Appl. Phys. Lett 1997, 70, 11, 1480-1482, Mar.

[38] Lee, S. W. et al., High-power lithium batteries from functionalized carbon-nanotube electrodes. Nat. Nanotechnol 2010, 5, 531, Jun.

[39] Kim, H., Park, K.-Y., Hong, J., Kang, K., All-graphene-battery: bridging the gap between supercapacitors and lithium ion batteries. Sci. Rep 2014, 4, 5278, Jun.

[40] Cheng,Q. , Okamoto, Y., Tamura, N., Tsuji, M., Maruyama, S., and Matsuo, Y., Graphene-likegraphite as fast-chargeable and high-capacity anode materials for lithium ion batteries. Sci. Rep 2017, 7, 1, 14782.

[41] Wang, S., Kravchyk, K. V, Krumeich, F., and Kovalenko, M. V, Kish graphite flakes as a cathode material for an aluminum chloride-graphite battery. ACS Appl. Mater. Interfaces 2017, 9, 34, 28478-28485, Aug.

[42] Yanwu, Zhu, Shanthi, Murali, Weiwei, Cai, Xuesong, Li, Ji Won, Suk, Jeffrey R, Potts, Rodney S., Ruoff, Graphene and graphene oxide: Synthesis, properties, and applications. Adv. Mater 2010, 22, 35, 3906-3924.

[43] Olivares-Marín, M. et al., Cherry stones as precursor of activated carbons for supercapacitors. Mater. Chem. Phys 2009, 114, 1, 323-327, Mar.

[44] Vivekchand, S. R. C., Rout, C. S., Subrahmanyam, K. S., Govindaraj, A., and Rao, C. N. R., Graphene-based electrochemical supercapacitors. J. Chem. Sci 2008, 120, 1, 9-13.

[45] Wick,P. et al., Classification framework for graphene-based materials. Angew. Chem. Int. Ed. Engl 2014. 
[46] Chyan, Y., Ye, R., Li, Y., Singh, S. P., Arnusch, C. J., and Tour, J. M., Laser-Induced graphene by multiple lasing: Toward electronics on cloth, paper, and food. ACS Nano 2018, 12, 3, 2176-2183, Mar.

[47] T. O. and Norio, M. K. Takami, Asako Satoh, Large hysteresis during lithium insertion into and extraction from high-capacity disordered carbons. J. Electrochem. Soc 1998, 145, 2, 478-482.

[48] Pan, Q., Deng, Z., Zhang, X., and Wan, G., Electrochemical characteristics of lithium intercalation into natural gas coke serving as the negative electrode of a lithium battery. J. Power Sources 1999, 79, 1, 25-29, May.

[49] Sato, Y. et al., Characteristics of coke carbon modified with mesophase-pitch as a negative electrode for lithium ion batteries. J. Power Sources 1999, 81-82, 182-186, Sep.

[50] Sharon, M. et al., Camphor-based carbon nanotubes as an anode in lithium secondary batteries. J. Power Sources 2002, 104, 1, 148-153, Jan.

[51] Kumar, M., Kichambare, P., Sharon, M., Avery, N. R., and Black, K. J., Study of camphorpyrolysed carbon electrode in a lithium rechargeable cell. Mater. Chem. Phys 2000, 66, 1, 83-89, Sep.

[52] Sunil Bhardwaj, M. S., Jaybhaye, Sandesh V., Madhuri Sharon, D. Sathiyamoorthy, K. Dasgupta, Jagadale, Pravin, Gupta, Arvind, Patil, Bhushan, Ozha, Goldie, Sunil Pandey, T. Soga, Rakesh Afre, Kalita, Golap, Carbon nanomaterial from tea leaves as an anode in lithium secondary batteries. Asian J. Exp. Sci 2008, 22, 2, 89-93.

[53] Yazami, R. and Touzain, P., A reversible graphite-lithium negative electrode for electrochemical generators. J. Power Sources 1983, 9, 3, 365-371, Jan.

[54] Skundin, A. M., Grigor'eva, O. Y., Kulova, T. L., and Pouchko, S. V, The lithium intercalation into graphite from electrolyte and from solid lithium. J. Solid State Electrochem 2003, 8, 1, 11-14.

[55] A. M. S. O. Yu. Grigor'eva, T. L. Kulova, S. V. Pushko, Lithium Intercalation into Graphite during Direct Contact and Anodic Polarization. Russ. J. Electrochem 2002, 38, 12, 1327-1333.

[56] Kulova, T. L., Skundin, A. M., Nizhnikovskii, E. A., and Fesenko, A. V, Temperature effect on the lithium diffusion rate in graphite. Russ. J. Electrochem 2006, 42, 3, 259-262.

[57] Roh, Y. B. et al., Unique charge/discharge properties of carbon materials with different structures. J. Power Sources 1997, 68, 2, 271-276, Oct.

[58] Morita, M., Nishimura, N., and Matsuda, Y., Charge/discharge cycling behavior of pitchbased carbon fiber in organic electrolyte solutions. Electrochim. Acta 1993, 38, 13, 1721-1726, Sep.

[59] Jean, R. M. M., Desnoyer, C., Tranchant, A., Electrochemical and Structural Studies of Petroleum Coke in Carbonate-Based Electrolytes. J. Electrochem. Soc 1995, 142, 7, 2122-2125.

[60] Takashi Uchida, K. S., Morikawa, Yasuyuki, Ikuta, Hiromasa, Wakihara, Masataka, Chemical Diffusion Coefficient of Lithium in Carbon Fiber. J. Electrochem. Soc 1996, 143, 8, 2606-2610.

[61] Aurbach, D., Levi, M. D., Levi, E., and Schechter, A., Failure and Stabilization Mechanisms of Graphite Electrodes. J. Phys. Chem. B 1997, 101, 12, 2195-2206, Mar.

[62] Levi, M. D. E. Levi, A., and Aurbach, D., The mechanism of lithium intercalation in graphite film electrodes in aprotic media. Part 2. Potentiostatic intermittent titration and in situ XRD studies of the solid-state ionic diffusion. J. Electroanal. Chem 1997, 421, 1-2, 89-97, Jan.

[63] Markovsky, B., Levi, M. D., and Aurbach, D., The basic electroanalytical behavior of practical graphite-lithium intercalation electrodes. Electrochim. Acta 1998, 43, 16-17, 2287-2304, May. 
[64] Barsoukov, E., Kim, J. H., Kim, J. H., Yoon, C. O., and Lee, H., Kinetics of lithium intercalation into carbon anodes: In situ impedance investigation of thickness and potential dependence. Solid State lonics 1999, 116, 3-4, 249-261, Jan.

[65] Churikov, A. V, Chronoamperometric determination of the rate of lithium transfer in carbon electrodes. Ehlektrokhimiya 2002, 38, 1, 120-125.

[66] C. D. and S. M. Piao, Tiehua, Parka, Su-Moon, Intercalation of Lithium Ions into Graphite Electrodes Studied by AC Impedance Measurements. J. Electrochem. Soc 1999, 146, 8, 2794-2798.

[67] J. A. R. and R. E. W. Ping Yu, B. N. Popov, Determination of the lithium ion diffusion coefficient in graphite. J. Electrochem. Soc 1999, 146, 1, 8-14.

[68] Lau, K. C., Assary, R. S., and Curtiss, L. A. , "Aprotic Electrolytes in Li-Air Batteries BT Electrolytes for Lithium and Lithium-Ion Batteries,” Jow, T. R., Xu, K., Borodin, O., and Ue, M., Eds. New York, NY: Springer New York, 2014, 445-466.

[69] Zolin, L. et al., A simple route toward next-gen green energy storage concept by nanofibresbased self-supporting electrodes and a solid polymeric design. Carbon N. Y 2016, 107, 811-822.

[70] Nair, J. R. et al., Remarkably stable high power Li-ion battery anodes based on vertically arranged multilayered-graphene. Electrochim. Acta 2015, 182.

[71] Wang, Y.-G., Chang, Y.-C., Ishida, S., Korai, Y., and Mochida, I., Stabilization and carbonization properties of mesocarbon microbeads (MCMB) prepared from a synthetic naphthalene isotropic pitch. Carbon N. Y 1999, 37, 6, 969-976, Jan.

[72] Guerin, K., Fevrier-Bouvier, A., Flandrois, S., Simon, B., and Biensan, P., On the irreversible capacities of disordered carbons in lithium-ion rechargeable batteries, Electrochim. Acta 2000, 45, 10, 1607-1615, Jan.

[73] Buiel, E. and Dahn, J., Li-insertion in hard carbon anode materials for Li-ion batteries. Electrochim. Acta 1999, 45, 1-2, 121-130, Sep.

[74] Appetecchi, G., Croce, F., Marassi, R., Persi, L., Romagnoli, P., Scrosati, B., Lithium insertion into carbonaceous materials and transition metal oxides from high performance polymer electrolytes. Electrochim. Acta 1999, 45, 1-2, 23-30, Sep.

[75] Sato, E. M. Noguchi, K, Demachi, M, A, Oki N, A mechanism of lithium storage in disordered carbons. Science (80-.) 1994, 22, 264 (5158), 556-568.

[76] Walker, S., Holliday AK, Hughes, G., "Comprehensive inorganic chemistry," in Carbon, T.-D. AF, Ed. Oxford: Pergamon Pres, 1973, 1173-1294.

[77] Liu, Y., Xue, J. S., Zheng, T., and Dahn, J. R., Mechanism of lithium insertion in hard carbons prepared by pyrolysis of epoxy resins. Carbon N. Y 1996, 34, 2, 193-200, Jan.

[78] Larcher, D., Mudalige, C., Gharghouri, M., and Dahn, J. R., Electrochemical insertion of Li and irreversibility in disordered carbons prepared from oxygen and sulfur-containing pitches. Electrochim. Acta 1999, 44, 23, 4069-4072, Jul.

[79] Gong, J., Wu, H., and Yang, Q., "Structural and electrochemical properties of disordered carbon prepared by the pyrolysis of poly(p-phenylene) below $1000 \mathrm{C}$ for the anode of a lithium-ion battery. Carbon N. Y 1999, 37, 9, 1409-1416, Jan.

[80] Buiel, E. R., George, A. E., and Dahn, J. R., Model of micropore closure in hard carbon prepared from sucrose. Carbon N. Y 1999, 37, 9, 1399-1407, Jan.

[81] Dahn, J. R., Xing, W., and Gao, Y., The 'falling cards model' for the structure of microporous carbons. Carbon N. Y 1997, 35, 6, 825-830, Jan.

[82] Zheng, T., Xing, W., and Dahn, J. R., Carbons prepared from coals for anodes of lithium-ion cells. Carbon N. Y 1996, 34, 12, 1501-1507, Jan.

[83] Gibaud, A., Xue, J. S., and Dahn, J. R., A small angle X-ray scattering study of carbons made from pyrolyzed sugar. Carbon N. Y 1996, 34, 4, 499-503, Jan. 
[84] Zheng, T. and Dahn, J. R., Hysteresis observed in quasi open-circuit voltage measurements of lithium insertion in hydrogen-containing carbons. J. Power Sources 1997, 68, 2, 201-203, Oct.

[85] Zhou, P., Papanek, P., Bindra, C., Lee, R., and Fischer, J. E., High capacity carbon anode materials: Structure, hydrogen effect, and stability. J. Power Sources 1997, 68, 2, 296-300, Oct.

[86] Chakrabarti, A. et al., Conversion of carbon dioxide to few-layer graphene. J. Mater. Chem 2011, 21, 26, 9491-9493.

[87] Seo, Hong-Kyu and Lee, Tae-Woo, Graphene growth from polymers. Carbon Lett 2013, 14, 3, 145-151.

[88] Sun, Z., Yan, Z., Yao, J., Beitler, E., Zhu, Y., and Tour, J. M., Growth of graphene from solid carbon sources. Nature 2010, 468,549, Nov.

[89] Ruan, G., Sun, Z., Peng, Z., and Tour, J. M., Growth of Graphene from Food, Insects, and Waste. ACS Nano 2011, 5, 9, 7601-7607, Sep.

[90] Seo, H.-K. et al., Value-added Synthesis of Graphene: Recycling Industrial Carbon Waste into Electrodes for High-Performance Electronic Devices. Sci. Rep 2015, 5, 16710, Nov.

[91] Guo, H.-L., Wang, X.-F., Qian, Q.-Y., Wang, F.-B., and Xia, X.-H., A Green Approach to the Synthesis of Graphene Nanosheets. ACS Nano 2009 3, 9, 2653-2659, Sep.

[92] Kim, Y. S. et al., Methane as an effective hydrogen source for single-layer graphene synthesis on Cu foil by plasma enhanced chemical vapor deposition. Nanoscale 2013, 5, 3, 1221-1226.

[93] Shah, J., Lopez-Mercado, J., Carreon, M. G., Lopez-Miranda, A., and Carreon, M. L., Plasma synthesis of graphene from mango peel. ACS Omega 2018, 3, 1, 455-463, Jan.

[94] Wang, J., Zhu, M., Outlaw, R. A., Zhao, X., Manos, D. M., and Holloway, B. C., Synthesis of carbon nanosheets by inductively coupled radio-frequency plasma enhanced chemical vapor deposition. Carbon N. Y 2004, 42, 14, 2867-2872, Jan.

[95] Wu, Y., Qiao, P., Chong, T., and Shen, Z., Carbon nanowalls grown by microwave plasma enhanced chemical vapor deposition. Adv. Mater 2002, 14, 1, 64-67.

[96] Brar, V. W. et al., Second-order harmonic and combination modes in graphite, single-wall carbon nanotube bundles, and isolated single-wall carbon nanotubes. Phys. Rev. B 2002, 66, 15, 155-418, Oct.

[97] Dresselhaus, M. S., Dresselhaus, G., Saito, R., and Jorio, A., Raman spectroscopy of carbon nanotubes. Phys. Rep 2005, 409, 2, 47-99, Mar.

[98] Damen, T. C., Porto, S. P. S., and Tell, B., Raman effect in zinc oxide. Phys. Rev 142, 2, 570-574, Feb.

[99] Galeener, F. L. and Lucovsky, G., Longitudinal optical vibrations in glasses: GeO2 and SiO2. Phys. Rev. Lett 1976, 37, 22, 1474-1478, Nov.

[100] Cançado, L. G. et al., Quantifying defects in graphene via raman spectroscopy at different excitation energies. Nano Lett 2011, 11, 8, 3190-3196, Aug.

[101] Graf, D. et al., Spatially resolved raman spectroscopy of single- and few-layer graphene. Nano Lett 2007, 7, 2, 238-242, Feb.

[102] Dresselhaus, M. S., Dresselhaus, G., Saito, R., and Jorio, A., Raman spectroscopy of carbon nanotubes. Phys. Rep 2005, 409, 2, 47-99, Mar.

[103] Ferrari, A. C. and Robertson, J., Interpretation of Raman spectra of disordered and amorphous carbon, Phys. Rev. B 2000, 61, 20, 14095-14107, May.

[104] Tan, P., Dimovski, S., and Gogotsi, Y., Raman scattering of non-planar graphite: arched edges, polyhedral crystals, whiskers and cones. Philos. Trans. R. Soc. London. Ser. A Math. Phys. Eng. Sci 2004, 362, 18-24, 2289 LP-2310, Nov. 
[105] Hiralal, P., Rius, G., Andrew, P., Yoshimura, M., and Amaratunga, G. A. J., Tailoring carbon nanostructure for high frequency supercapacitor operation. J. Nanomater 2014, 8, 1-7, Jan.

[106] Rius, G. and Yoshimura, M., Synthesis control for carbon nanowalls on copper supports pro development of green energy applications. e-Journal Surf. Sci. Nanotechnol 2012, 10, 305-309.

[107] Rius, G. and Yoshimura, M., Structured nanocarbon on various metal foils by microwave plasma enhanced chemical vapor deposition. J. Phys. Conf. Ser 2013, 417, 012-010, Mar.

[108] Tobjörk, D. and Österbacka, R., Paper electronics. Adv. Mater 23, 17, 1935-1961, May 2011.

[109] Liu, J. et al., Future paper based printed circuit boards for green electronics: fabrication and life cycle assessment, Energy Environ. Sci 2014, 7, 11, 3674-3682, Oct.

[110] Jabbour, L., Bongiovanni, R., Chaussy, D., Gerbaldi, C., and Beneventi, D., Cellulose-based Liion batteries: A review. Cellulose 2013, 20, 4, 1523-1545, Aug.

[111] Berecibar, M., Gandiaga, I., Villarreal, I., Omar, N., Van Mierlo, J., and Van den Bossche, P., Critical review of state of health estimation methods of Li-ion batteries for real applications. Renew. Sustain. Energy Rev 2016, 56, 572-587, Apr.

[112] Sharifi, F., Ghobadian, S., Cavalcanti, F. R., and Hashemi, N., Paper-based devices for energy applications. Renew. Sustain. Energy Rev 2015, 52, 1453-1472, Dec.

[113] Hu, L. and Cui, Y., Energy and environmental nanotechnology in conductive paper and textiles. Energy Environ. Sci 2012, 5, 4, 6423-6435, Mar.

[114] Beneventi, D. et al., Pilot-scale elaboration of graphite/microfibrillated cellulose anodes for Li-ion batteries by spray deposition on a forming paper sheet. Chem. Eng. J 2014, 243, 372-379, May.

[115] Blazsó, M., Pyrolysis for recycling waste composites. Manag. Recycl. Reuse Waste Compos 2010, 102-121, Jan.

[116] Zolin, L. et al., Flexible cellulose-based electrodes: Towards eco-friendly all-paper batteries. Chem. Eng. trans. 2014, 41, 361-366.

[117] Gotoh, K. et al., Properties of a novel hard-carbon optimized to large size Li ion secondary battery studied by 7 Li NMR. J. Power Sources 2006, 162, 2, 1322-1328, Nov.

[118] Peled, E., The electrochemical behavior of alkali and alkaline earth metals in nonaqueous battery systems - the solid electrolyte interphase model. J. Electrochem. Soc 1979, 126, 12, 2047-2051, Dec.

[119] Kirshenbaum, K., et al. Batteries. In situ visualization of $\mathrm{Li} / \mathrm{Ag}_{2} \mathrm{VP}_{2} \mathrm{O}_{8}$ batteries revealing ratedependent discharge mechanism. Science 2015, 347, 6218, 149-54, Jan. 
